Check for updates

Cite this: RSC Adv., 2019, 9, 18663

\title{
New Leishmania donovani nucleoside hydrolase inhibitors from Brazilian flora $\uparrow$
}

\author{
Charlotte Nirma, (D) a Gregorio Torres Rangel, (D) a Marina Amaral Alves, (D) ab \\ Livia Marques Casanova, (iD a Mayara Monteiro Moreira, ${ }^{a}$ Luanna Monteiro Rodrigues, ${ }^{a}$ \\ Lidilhone Hamerski (D) and Luzineide Wanderley Tinoco (D) *a
}

\begin{abstract}
This study presents new inhibitors of the nucleoside hydrolase from Leishmania donovani (LdNH) with in vitro leishmanicidal activity. Biological screening of 214 Brazilian plant extracts was performed to select plants with enzyme inhibitory activity. Two plants were selected for their results, and for their lack of prior phytochemical description: Leandra amplexicaulis DC. (Melastomataceae) and Urvillea rufescens Cambess (Sapindaceae). Three flavonoids were isolated by bioguided fractionation of the hydroethanolic extracts: kaempferol 3-O- $\alpha$-L-rhamnopyranoside (1) and kaempferol 3-O- $\beta$-D-xylopyranosyl-(1 $\rightarrow 2)-\alpha-L-$ rhamnopyranoside (2) from L. amplexicaulis, as well as tricetin-4'-O-methyl flavone (3) from $U$. rufescens. These flavonoids showed inhibitory activities ( $\left.\mathrm{C}_{50}\right)$ of $197.4 \mu \mathrm{M}$ (1), $74.7 \mu \mathrm{M}(2)$ and $1.1 \mu \mathrm{M}$ (3) on the $L d \mathrm{NH}$. Their binding mode was proposed based on molecular docking with $L d \mathrm{NH}$ and by NMR Saturation Transfer Difference studies. Kinetic studies demonstrate that the most potent inhibitor (3) acts by uncompetitive inhibition. This study reports for the first time the inhibition of $L d N H$ by naturally sourced flavonoids.
\end{abstract}

Received 29th March 2019
Accepted 5th June 2019

DOI: $10.1039 / \mathrm{c} 9 \mathrm{ra02382h}$

rsc.li/rsc-advances
$L d \mathrm{NH}$ hydrolyses $\mathrm{N}$-riboglycoside bonds to provide the parasite with purine and pyrimidine bases for its DNA biosynthesis. Nucleoside hydrolase enzymes have not been identified in mammals, thus ensuring the selectivity of potential inhibitors. Moreover, $L d \mathrm{NH}$ shows high sequence similarity among different species of Leishmania and even other trypanosomatids. ${ }^{5,7,8}$ Due to the close genetic nature of different parasite species, this biochemical target could be conserved in other trypanosomatid parasites, allowing the discovery of a global antiprotozoal drug, with pan-trypanocidal activity. ${ }^{5}$

The purpose of our work is to isolate and characterize molecules from plants collected in the Atlantic Forest of the state of Rio de Janeiro (Brazil) capable of inhibiting the $L d \mathrm{NH}$ of Leishmania donovani. The use of plants for the discovery of new bioactive compounds, and the search for antileishmanial molecules from natural sources has been widely reported in the literature. ${ }^{9-13}$ A large percentage of these compounds were identified using in vitro assays against promastigotes or intracellular amastigotes of several species of Leishmania. However, to our knowledge there are no prior reports in which naturally occurring compounds were tested against the target $L d \mathrm{NH}$.

This study presents the results of biological screening, guided by the inhibitory activity of $L d \mathrm{NH}$, of 214 extracts of samples belonging to the I-FLORA project. I-FLORA is an interinstitutional and interdisciplinary project that aims to inventory the flora from Atlantic Forest of the state of Rio de Janeiro and add value to its diversity through chemical and biological studies.

\footnotetext{
${ }^{a}$ Universidade Federal do Rio de Janeiro, Instituto de Pesquisas de Produtos Naturais, Laboratório de Análise e Desenvolvimento de Inibidores Enzimáticos, Centro de Ciências da Saúde, 21941-902 Rio de Janeiro, RJ, Brazil. E-mail: lwtinoco@nppn. ufri.br

${ }^{b}$ Universidade Federal do Rio de Janeiro, Instituto de Ciências Biomédicas, Laboratório de Avaliação e Síntese de Substâncias Bioativas, Centro de Ciências da Saúde, 21941902 Rio de Janeiro, RJ, Brazil

$\dagger$ Electronic supplementary information (ESI) available: NMR spectra and $\mathrm{IC}_{50}$ curves. See DOI: 10.1039/c9ra02382h
} 
Among the most active extracts, two were selected for phytochemical analysis, Leandra amplexicaulis and Urvillea rufescens. L. amplexicaulis, popular name "pixirica", ${ }^{\mathbf{1 4}, \mathbf{1 5}}$ is a shrub distributed in the Atlantic Forest in the southeast (Minas Gerais, Espírito Santo, São Paulo, Rio de Janeiro) and south (Paraná, Santa Catarina) of Brazil. U. rufescens Cambess is a clambering plant native to the southeast and northeast regions of Brazil. ${ }^{16}$ To our knowledge, no phytochemical study has been carried out on either of these plants. Biodirected fractionation of the extracts allowed the isolation of three bioactive flavonoids. Flavonoids are already widely described for their bioactive properties, including those described as inhibitors of nucleoside hydrolases of Trichomonas vaginalis, ${ }^{\mathbf{1 7}, 18}$ as well as their leishmanicidal activities. ${ }^{11,19-21}$

To further elucidate the mechanism of action, we used molecular docking and NMR Saturation Transfer Difference (STD) experiments ${ }^{22}$ to analyze the interactions of the isolated active compounds with $L d \mathrm{NH}$. These techniques provide insights into the nature of intermolecular interactions and can be used to map ligand-protein contacts.

\section{Experimental}

\subsection{General experimental procedures}

Optical rotation was measured with a Jasco P-2000 Polarimeter. NMR spectra were recorded using Agilent VNMRS-500 or 400 MR spectrometers. Chemical shifts $(\delta)$ are reported in $\mathrm{ppm}$ relative to the tetramethylsilane (TMS) resonance $(0.00 \mathrm{ppm})$. High-resolution ESI-TOF-MS measurements were performed using a Shimadzu UPLC system equipped with a Poroshell ECC18 $2.7 \mu \mathrm{m} 2.1 \times 100 \mathrm{~mm}$ column. The $7 \mathrm{~min}$ separation was carried out by isocratic elution using $\mathrm{MeOH}$ at a flow rate of 300 $\mu \mathrm{L} \min ^{-1}$. The UPLC was coupled to a Shimadzu time-of-flight (TOF) mass spectrometer equipped with an electrospray (ESI) interface. TLC analyses were conducted on 60A F254 Merck plates, visualized under UV light (254 and $365 \mathrm{~nm}$ ) and revealed with iodine. Analytical and semi-preparative HPLC analyzes were performed with Varian or Shimadzu systems using a linear gradient. All solvents were HPLC grade (TEDIA $\left.{ }^{\circledR}\right)$ and were prepared by addition of $0.05 \%$ acetic acid. Columns used for these experiments included Phenomenex Luna PhenylHexyl 5 $\mu \mathrm{m} 4.6 \times 250 \mathrm{~mm}$ analytical columns and Phenomenex Luna PhenylHexyl $5 \mu \mathrm{m} 10 \times 250 \mathrm{~mm}$ and C18 $5 \mu \mathrm{m} 21.2 \times 250 \mathrm{~mm}$ semi-preparative columns.

\subsection{Plant material and extraction}

Plant species screened in the present study as part of the I-Flora project were collected in the Atlantic Forest from the state of Rio de Janeiro, Brazil from 2009 to 2012. Plant material (from branches, leaves or stems) was dried at room temperature for $48 \mathrm{~h}$. Subsequently, the material was ground and macerated three times with ethanol/water $10 \%(\mathrm{v} / \mathrm{v})$ at room temperature for $96 \mathrm{~h}: 48 \mathrm{~h}$ for the first extraction and $24 \mathrm{~h}$ the other two extractions.

The screening step was performed with a total of 214 hydroethanolic extracts to evaluate their inhibitory activity for
$L d \mathrm{NH}$. Based on these initial results, two extracts were selected for bioguided fractionation: the extract of the flowers of Leandra amplexicaulis DC (Melastomataceae) and the leaf extract of Urvillea rufescens Cambess (Sapindaceae).

L. amplexicaulis was collected on April 15, 2012 in the Parque Nacional do Itatiaia, Itatiaia $(-22.397309,-44.612180)$ in the state of Rio de Janeiro by Prof. Dr Marcelo Trovó Lopes de Oliveira from the Federal University of Rio de Janeiro. The plant was authenticated by Dr Trovó and a voucher specimen (RB639928) deposited at the herbarium of the Botanical Garden of Rio de Janeiro.

U. rufescens was collected in the Grumari Municipal Nature Park, Rio de Janeiro, Rio de Janeiro state (-23.054992, -43.549446), by Prof. Dr Genise Vieira Somner from the Federal Rural University of Rio de Janeiro (UFRRJ). The plant was authenticated by Dr Somner and a voucher specimen, (RBR 42621) was deposited at the herbarium of the Federal Rural University of Rio de Janeiro (UFRRJ).

\subsection{Extraction and isolation of constituents}

2.3.1 Leandra amplexicaulis flower extract. The hydroethanolic extract $(1.47 \mathrm{~g})$ was subjected to solvent partition separation between $n$-hexane and $8: 2 \mathrm{MeOH} / \mathrm{H}_{2} \mathrm{O}$ followed by $\mathrm{CH}_{2} \mathrm{Cl}_{2}$ and $8: 2 \mathrm{MeOH} / \mathrm{H}_{2} \mathrm{O}$, and then AcOEt and $6: 4 \mathrm{MeOH} /$ $\mathrm{H}_{2} \mathrm{O}$. The final AcOEt fraction $(383.8 \mathrm{mg}$ ) proved to be the best source of $L d \mathrm{NH}$ inhibitory constituents. The AcOEt fraction was subjected to semi-preparative HPLC [column: PhenylHexyl; mobile phase: $20: 80 \mathrm{CH}_{3} \mathrm{CN} / \mathrm{H}_{2} \mathrm{O}+0.05 \% \mathrm{HOAc}$ to $40: 60$ using a linear gradient over $20 \mathrm{~min}$ followed by $100 \% \mathrm{CH}_{3} \mathrm{CN}$ for

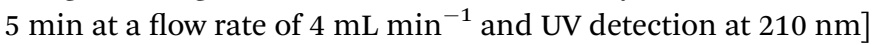
to yield four subfractions (A-D). Subfraction $\mathrm{C}$ showed the best inhibitory activity with $79 \%$ of the total inhibition. Fraction $\mathrm{C}$ (46.2 $\mathrm{mg}$ ) was subjected to semi-preparative HPLC [column PhenylHexyl; mobile phase: $30: 70 \mathrm{CH}_{3} \mathrm{CN} / \mathrm{H}_{2} \mathrm{O}+0.05 \%$ HOAc to $60: 40$ using a linear gradient over $20 \mathrm{~min}$ at a flow rate of 2 $\mathrm{mL} \min ^{-1}$ and UV detection at $210 \mathrm{~nm}$ ] to yield compounds 1 (6.1 $\mathrm{mg}, \mathrm{RT}=12 \mathrm{~min}$ ) and $2(14 \mathrm{mg}, \mathrm{RT}=10 \mathrm{~min})$.

Kaempferol 3-O- $\alpha$-L-rhamnoside (1). Yellowish oil; $[\alpha]_{\mathrm{D}}^{25}-116.9$ (c 0.2, $\mathrm{MeOH}) ;{ }^{1} \mathrm{H} \mathrm{NMR}\left(500 \mathrm{MHz}, \mathrm{CD}_{3} \mathrm{OD}\right): 7.77(2 \mathrm{H}, \mathrm{d}, J=9 \mathrm{~Hz}$, $\left.\mathrm{H}-2^{\prime} / \mathrm{H}-6^{\prime}\right), 6.94\left(2 \mathrm{H}, \mathrm{d}, J=9 \mathrm{~Hz}, \mathrm{H}-3^{\prime} / \mathrm{H}-5^{\prime}\right), 6.38(1 \mathrm{H}, \mathrm{d}, J=2 \mathrm{~Hz}$, $\mathrm{H}-8), 6.21(1 \mathrm{H}, \mathrm{d}, J=2 \mathrm{~Hz}, \mathrm{H}-6), 5.38\left(1 \mathrm{H}, \mathrm{d}, J=1.0 \mathrm{~Hz}, \mathrm{H}-1^{\prime \prime}\right)$, $4.22\left(1 \mathrm{H}, \mathrm{dd}, J=2.7 ; 1.0 \mathrm{~Hz}, \mathrm{H}-2^{\prime \prime}\right), 3.70\left(1 \mathrm{H}, \mathrm{m}, \mathrm{H}-3^{\prime \prime}\right), 3.33(1 \mathrm{H}$, m, H-4 $\left.4^{\prime \prime}\right), 3.32\left(1 \mathrm{H}, \mathrm{m}, \mathrm{H}-5^{\prime \prime}\right), 0.92\left(3 \mathrm{H}, \mathrm{d}, J=6 \mathrm{~Hz}, \mathrm{H}-6^{\prime \prime}\right) ;{ }^{13} \mathrm{C}$ NMR (125 MHz, CD 3 OD): n.d. (C-4), 164.7 (C-7), 162.2 (C-5), 160.8 (C-4'), 157.8 (C-2), 157.6 (C-9), 134.8 (C-3), 131.5 (C-2'/C$\left.6^{\prime}\right), 120.7$ (C-1'), 116.1 (C-3'/C-5'), 104.8 (C-10), 103.8 (C-1"), 99.5

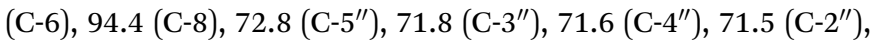

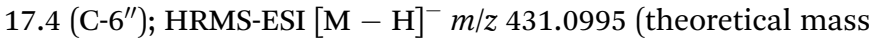
for $\left.\mathrm{C}_{21} \mathrm{H}_{19} \mathrm{O}_{10}, 431.0984\right)$.

Kaempferol 3-O- $\beta$-D-xylopyranosyl-(1 $\rightarrow 2)-\alpha-L$-rhamnopyranoside (2). Yellowish oil; $[\alpha]_{\mathrm{D}}^{25}-10(c 0.16, \mathrm{MeOH}) ;{ }^{1} \mathrm{H}$ NMR (500 $\left.\mathrm{MHz}, \mathrm{CD}_{3} \mathrm{OD}\right): 7.77\left(2 \mathrm{H}, \mathrm{d}, J=8.6 \mathrm{~Hz}, \mathrm{H}-2^{\prime} / \mathrm{H}-6^{\prime}\right), 6.95(2 \mathrm{H}, \mathrm{d}, J=$ $\left.8.6 \mathrm{~Hz}, \mathrm{H}-3^{\prime} / \mathrm{H}^{-} 5^{\prime}\right), 6.38(1 \mathrm{H}, \mathrm{d}, J=1.9 \mathrm{~Hz}, \mathrm{H}-8), 6.20(1 \mathrm{H}, \mathrm{d}, J=$ $1.9 \mathrm{~Hz}, \mathrm{H}-6), 5.43\left(1 \mathrm{H}, \mathrm{d}, J=1.3 \mathrm{~Hz}, \mathrm{H}-1^{\prime \prime}\right), 4.29(1 \mathrm{H}, \mathrm{d}, J=$ $\left.7.6 \mathrm{~Hz}, \mathrm{H}-1^{\prime \prime \prime}\right), 4.20$ (1H, dd, $\left.J=3.6 ; 1.3 \mathrm{~Hz}, \mathrm{H}-2^{\prime \prime}\right), 3.83$ (1H, dd, $J$ $\left.=9.9 ; 3.6 \mathrm{~Hz} \mathrm{H}-3^{\prime \prime}\right), 3.68$ (1H, m, H-5"' a), 3.67 (1H, m, H-5 $\left.{ }^{\prime \prime}\right), 3.41$ 
(1H, ddd, $\left.J=11.1 ; 8.8 ; 5.4 \mathrm{~Hz}, \mathrm{H}-4^{\prime \prime \prime}\right), 3.34(1 \mathrm{H}, \mathrm{d}, J=9.9 \mathrm{~Hz}, \mathrm{H}-$ $\left.4^{\prime \prime}\right), 3.28\left(1 \mathrm{H}, \mathrm{d}, J=8.8 \mathrm{~Hz}, \mathrm{H}-3^{\prime \prime \prime}\right), 3.19(1 \mathrm{H}, \mathrm{dd}, J=8.8 ; 7.6 \mathrm{~Hz}$, $\left.\mathrm{H}-2^{\prime \prime \prime}\right), 3.09$ (1H, dd, $\left.J=11.1 \mathrm{~Hz}, \mathrm{H}-5^{\prime \prime \prime} \mathrm{b}\right), 1.00(3 \mathrm{H}, \mathrm{d}, J=6.2 \mathrm{~Hz}$, H-6"); ${ }^{13} \mathrm{C}$ NMR (125 MHz, CD $3 \mathrm{OD}$ ): 178.10 (C-4), 164.49 (C-7), 161.72 (C-5), 160.24 (C-4'), 157.99 (C-2), 157.07 (C-9), 135.48 (C-3), 130.44 (C-2'/C-6'), $121.11\left(\mathrm{C}-1^{\prime}\right), 115.15\left(\mathrm{C}-3^{\prime} / \mathrm{C}-5^{\prime}\right), 104.61$ (C-10), 106.32 (C-1"' ), $101.71\left(\mathrm{C}-1^{\prime \prime}\right), 98.43$ (C-6), 93.36 (C-8), $81.22\left(\mathrm{C}-2^{\prime \prime}\right), 76.33\left(\mathrm{C}-3^{\prime \prime \prime}\right), 73.85\left(\mathrm{C}-2^{\prime \prime \prime}\right), 72.17\left(\mathrm{C}-4^{\prime \prime}\right), 70.50(\mathrm{C}-$ $\left.3^{\prime \prime}\right), 70.46\left(\mathrm{C}-5^{\prime \prime}\right), 69.54\left(\mathrm{C}-4^{\prime \prime \prime}\right), 65.66\left(\mathrm{C}-5^{\prime \prime \prime}\right), 16.28$ (C-6"); HRMSESI $[\mathrm{M}-\mathrm{H}]^{-} m / z 563.1402$ (theoretical mass for $\mathrm{C}_{26} \mathrm{H}_{27} \mathrm{O}_{14}$, 563.1406).

2.3.2 Urvillea rufescens leaves extract. The hydroethanolic extract $(5.89 \mathrm{~g})$ was subjected to solvent partition separation between $n$-hexane and $8: 2 \mathrm{MeOH} / \mathrm{H}_{2} \mathrm{O}$ followed by AcOEt and $6: 4 \mathrm{MeOH} / \mathrm{H}_{2} \mathrm{O}$. The final AcOEt fraction $(2.04 \mathrm{~g})$ proved to be the best source of $L d \mathrm{NH}$ inhibitory constituents. $243 \mathrm{mg}$ of the AcOEt fraction was dissolved in $5 \mathrm{~mL}$ AcOEt/MeOH and centrifuged. The supernatant was introduced onto a Sephadex® LH20 column $(77 \times 3.5 \mathrm{~cm})$ for size exclusion chromatography using $7: 3$ AcOEt/MeOH as the mobile phase. This separation produced 15 subfractions (A-N). Subfraction F showed the best inhibitory activity with $93.4 \%$ of the total inhibition. F $(15.2 \mathrm{mg})$ was purified by analytical HPLC using a $250 \times 4.6 \mathrm{~mm}$ Phenomenex® Phenyl Hexyl Luna column with $100 \AA$ pore size and $5 \mu \mathrm{m}$ particle size. The separation was carried out using isocratic elution with $50: 50\left(\mathrm{MeOH}: \mathrm{H}_{2} \mathrm{O}\right)$ to yield compound 3 (0.7 mg, RT: $14 \mathrm{~min}$ ).

As 3 presented high $L d \mathrm{NH}$ inhibitory activity, the purification process was modified to obtain greater quantities of the substance, enabling further assays. Thus, $500 \mathrm{mg}$ of the AcOEt fraction was dissolved in $5 \mathrm{~mL}$ AcOEt/MeOH, and centrifuged. The supernatant was introduced onto a Sephadex ${ }^{\circledR}$ LH20 column $(70 \times 3.5 \mathrm{~cm})$ eluted with $7: 3 \mathrm{AcOEt} / \mathrm{MeOH}$ and then switched to $100 \% \mathrm{MeOH}$, which yielded five subfractions (I-V). Fraction V $(65.5 \mathrm{mg})$ was enriched in the flavonoid of interest and was selected for further purification. Fraction $\mathrm{V}$ was introduced onto a reverse phase $\mathrm{C}-18$ solid phase extraction cartridge ( $1 \mathrm{~g} ; 6 \mathrm{~mL}$; Bakerbond ${ }^{\circledR}$ ) and eluted using a series of water/ methanol solutions: $1: 9 \mathrm{MeOH} / \mathrm{H}_{2} \mathrm{O}, 3: 7 \mathrm{MeOH} / \mathrm{H}_{2} \mathrm{O}, 1: 1$ $\mathrm{MeOH} / \mathrm{H}_{2} \mathrm{O}, 7: 3 \mathrm{MeOH} / \mathrm{H}_{2} \mathrm{O}$ and $\mathrm{MeOH}$. Thus, it was possible to obtain $7.7 \mathrm{mg}$ of compound 3 , which was eluted from the cartridge with $1: 1 \mathrm{MeOH} / \mathrm{H}_{2} \mathrm{O}$.

Tricetin 4-O-methyl-flavone (3). Yellowish oil. ${ }^{1} \mathrm{H}$ NMR (400 $\left.\mathrm{MHz}, \mathrm{CD}_{3} \mathrm{OD}\right): 6.97$ (2H, s, H-2'/H-6 $), 6.52(1 \mathrm{H}, \mathrm{s}, \mathrm{H}-3), 6.41(1 \mathrm{H}$, $\mathrm{d}, J=1.9 \mathrm{~Hz}, \mathrm{H}-8), 6.19(1 \mathrm{H}, \mathrm{d}, J=1.9 \mathrm{~Hz}, \mathrm{H}-6), 3.88(3 \mathrm{H}, \mathrm{s}, \mathrm{O}-$ $\mathrm{CH}_{3}$ ); ${ }^{13} \mathrm{C}$ NMR (100 MHz, $\mathrm{CD}_{3} \mathrm{OD}$ ): 182.19 (C-4), 166.05 (C-7), 164.12 (C-2), 161.87 (C-5), 158.13 (C-9), $150.92\left(\mathrm{C}-3^{\prime} / \mathrm{C}-5^{\prime}\right)$, 138.84 (C-4'), 126.39 (C-1'), 105.43 (C-2'/C-6'), 103.53 (C-3/C-10), 99.18 (C-6), 94.14 (C-8), $59.37\left(\mathrm{O}-\mathrm{CH}_{3}\right)$. ESI $[\mathrm{M}-\mathrm{H}]^{-} \mathrm{m} / z 315.03$ (theoretical mass for $\mathrm{C}_{16} \mathrm{H}_{12} \mathrm{O}_{7}, 316.0583$ ).

2.3.3 Protein expression and purification. Recombinant $L d \mathrm{NH}$ was expressed in Escherichia coli BL21(DE3) and purified by nickel affinity chromatography as previously described. ${ }^{6}$ After purification, the fractions containing nucleoside hydrolase activity were pooled, dialyzed against $20 \mathrm{mM}$ phosphate buffer pH 7.4 and $200 \mathrm{mM} \mathrm{NaCl}$, and concentrated by ultrafiltration. After quantification by the Lowry method, ${ }^{23}$ protein was stored at $-80{ }^{\circ} \mathrm{C}$. Protein purity was estimated as $>90 \%$ by SDSPAGE electrophoresis with Coomassie brilliant blue staining.

2.3.4 Measurement of enzyme kinetics with UV spectrophotometry. Kinetics measurements were carried out with a UVvisible spectrophotometer (SpectraMax Molecular devices M5) using Greiner 96 well plates as previously described.6,24 The saturation curve was obtained by plotting the initial velocity $v s$. the substrate concentration and analyzed by nonlinear regression with GraphPad Prism using the Michaelis-Menten equation to determine the values of $V_{\max }$ and $K_{\mathrm{M}}$.

2.3.5 Nucleoside hydrolase inhibition assay. All crude extracts were first tested at $100 \mu \mathrm{g} \mathrm{mL}^{-1}$ and those showing $50 \%$ inhibition or higher, in three different replicate measurements, were further evaluated with the xanthine oxidase (XO) inhibition assay to determine the concentration necessary for $50 \%$ inhibition $\left(\mathrm{IC}_{50}\right)$. The extracts used in the XO assay contained a final DMSO concentration of $0.5 \%$. The appropriate control experiments were performed and indicated that a concentration of $2 \%$ DMSO did not affect the enzyme assay.

2.3.6 LdNH inhibition. The initial velocity for inosine hydrolysis in the presence of extract $\left(V_{0} \mathrm{e}\right)$ was determined in triplicate measurements by addition of $26 \mathrm{nM} L d \mathrm{NH}$ to $0.5 \mathrm{mM}$ inosine, $120 \mathrm{mU}$ of XO (excess) and $0.1 \mathrm{mg} \mathrm{mL}^{-1}$ of crude extract in $20 \mathrm{mM}$ pH 7.4 phosphate buffer at a final volume of $200 \mu \mathrm{L}$. Uric acid formation was monitored at $293 \mathrm{~nm}$ at room temperature. The percentage of inhibition is calculated from the initial velocity of the control $\left(V_{0} \mathrm{c}\right)$ according to the equation $\%$ inhibition $=\left(1-V_{0} \mathrm{e} / V_{0} \mathrm{c}\right) \times 100$.

2.3.7 Determination of $\mathbf{I C}_{50}$. Values of $\mathrm{IC}_{50}$ were independently determined by rate measurements for at least seven concentrations of extracts with fixed concentrations of $L d \mathrm{NH}$ (26 $\mathrm{nM})$ and inosine $(0.5 \mathrm{mM})$. The data were analyzed by nonlinear regressing using the GraphPad prism Software.

2.3.8 Type of enzymatic inhibition. The reversibility of the enzymatic inhibition of the most active flavonoid, 3, was assessed by analyzing for the complex E-I, ${ }^{25}$ as described previously by our group. ${ }^{24}$ The stability of E-I was evaluated by pre-incubating compound 3 at concentrations $\sim 10$ times higher than the $\mathrm{IC}_{50}$ together with $0.2 \mathrm{mg} \mathrm{mL}{ }^{-1} L d \mathrm{NH}$ (100 times higher than the usual concentration for incubation) in phosphate buffer (20 mM pH 7.4, $300 \mathrm{mM} \mathrm{NaCl}$ ). After 20 minutes, a "jump dilution" was performed and the reaction was initiated by adding $93 \mu \mathrm{g} \mathrm{mL} \mathrm{m}^{-1} \mathrm{XO}$ and $0.3 \mathrm{mM}$ inosine in phosphate buffer to effect a 100 fold dilution of compound 3 and the enzyme. The reversibility of the inhibition was assessed measuring the recovery of the enzymatic activity compared to control samples without inhibitor during the pre-incubation step. The same experimental conditions were used to determine the type of enzymatic inhibition. In this case, five concentrations of inosine $(0.03,0.1,0.3,1$, and $3 \mathrm{mM})$ were used in the absence (control) and presence of three fixed concentrations of the inhibitor $(4,2$ and $1 \mu \mathrm{M})$, selected according to the $\mathrm{IC}_{50}$. The data were analyzed by non-linear regression to compare different classical models of inhibition and select the model with the best fit using the Akaike criteria (GraphPad Prism version 5.0). 
2.3.9 NMR spectroscopy. NMR spectra were acquired on an Agilent VNMRS-500 $\left({ }^{1} \mathrm{H}-499.79 \mathrm{MHz},{ }^{13} \mathrm{C}-125.68 \mathrm{MHz}\right)$ or 400 MR $\left({ }^{1} \mathrm{H}-399.74 \mathrm{MHz},{ }^{13} \mathrm{C}-100.52 \mathrm{MHz}\right)$ at $25{ }^{\circ} \mathrm{C}$. For STD analyses, $L d \mathrm{NH}$ was added at a final concentration of $100 \mu \mathrm{M}$ and isolated compounds were present at $2 \mathrm{mM}$. Samples were prepared in $20 \mathrm{mM}$ phosphate buffer at $\mathrm{pH} 7.4$ in $90 \% \mathrm{H}_{2} \mathrm{O} / 10 \%$ $\mathrm{D}_{2} \mathrm{O}$. Water signal suppression was performed by DPFGSE pulse sequence $^{26}$ included in the STD pulse sequence. ${ }^{22}$ Spectra were acquired in alternated scans with off-resonance irradiation at $20 \mathrm{ppm}$ and on-resonance at $-1 \mathrm{ppm}$. Evaluation of saturation times between 1 and $5 \mathrm{~s}$ showed that a saturation time of $2 \mathrm{~s}$ led to the most efficient transfer of saturation from the protein to the ligand protons. Therefore, all STD spectra were recorded using a 2 s saturation time and 1024 scans. All spectra were processed with MestReNova 10.0.1.

2.3.10 Molecular docking. Flavonoid 3 was drawn using Spartan'14 and the ligand-target binding modes investigated using the SwissDock web server ${ }^{27}$ and the homology model previously described. ${ }^{6}$ The analysis of molecular docking solutions was performed using the programs Chimera 1.10.2 and Pymol 1.5.0.5.

\section{Results and discussion}

As part of the I-Flora project, we investigated 214 hydroethanolic plant extracts for their $L d \mathrm{NH}$ inhibitory activity. Twenty-eight extracts inhibited $L d \mathrm{NH}$ by $50 \%$ or more at a concentration of $100 \mu \mathrm{g} \mathrm{mL}{ }^{-1}$ (Fig. S1 $\dagger$ ). Due to the absence of prior phytochemical studies, extracts of the flowers of Leandra amplexicaulis DC (Melastomataceae) and the leaves of Urvillea rufescens Cambess (Sapindaceae) were selected from among the most active extract for further interrogation.

Following the bioguided fractionation of L. amplexicaulis extract, two substances ( $\mathbf{1}$ and 2 ) were isolated and identified by 1D and 2D NMR and mass spectrometry (see Experimental section). Both molecules have an aglycone flavonoid structure substituted with one or two sugars (Fig. 1). Compound 1 has a kaempferol skeleton with a rhamnopyranosyl unit, suggested by a characteristic methyl doublet at $\delta 0.92(J=6 \mathrm{~Hz})$. It was identified by comparison to literature data as kaempferol $3-O-\alpha-$ L-rhamnopyranoside (afzelin). ${ }^{28}$

The structure of compound 2 was elucidated based on ${ }^{1} \mathrm{H}$ and ${ }^{13} \mathrm{C}-\mathrm{NMR}$ data and mass spectrometry. The ${ }^{1} \mathrm{H}$ and HSQC

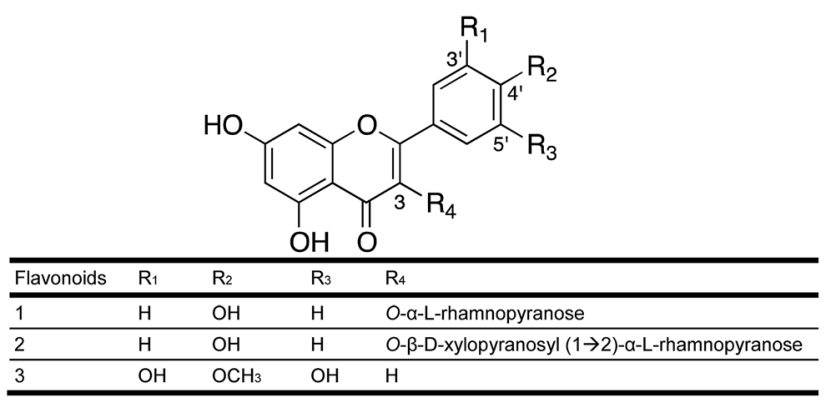

Fig. 1 Molecular structure of the isolated flavonoids 1-3.
NMR spectra are available in the ESI (Fig. S2A and $\mathrm{B}^{\dagger}$ ). Compound 2 also has a kaempferol skeleton with a rhamnose and a xylopyranose linked at C-3. It was identified as kaempferol 3 - $O$ - $\beta$-D-xylopyranosyl- $(1 \rightarrow 2)-\alpha$-L-rhamnopyranoside in accordance with literature data. ${ }^{29}$ This diglycosylated flavonol was first described in the leaves of Moghania faginea (Fabaceae), ${ }^{\mathbf{9}}$ then from the medicinal plant Kalanchoe daigremontiana ${ }^{30}$ and subsequently from Pourthiaea villosa ${ }^{31}$ along with 1 . The 3-Oglycosides of kaempferol are the most common group of flavonoids.

Following the bioguided fractionation of $U$. rufescens, compound 3 (Fig. 1) was isolated and identified by $1 \mathrm{D}$ and $2 \mathrm{D}$ NMR and mass spectrometry. The HSQC NMR spectrum is available in the ESI (Fig. S3†). According to these spectra and in comparison, with the literature, we concluded that the structure of compound 3 is a free aglycone named tricetin- $4^{\prime}-O$-methyl flavone. This flavone was first isolated from Passiflora palmeri Rose (Passifloraceae) ${ }^{32}$ and then from Heliotropium pycnophyllum (Boraginaceae). ${ }^{33}$

The inhibitory activities ( $\mathrm{IC}_{50}$ ) of compounds $\mathbf{1 ,} 2$ and 3 for $L d \mathrm{NH}$ were determined by spectroscopic analysis at $293 \mathrm{~nm}$ in an enzymatic assay coupled with xanthine oxidase. Both flavonoids with kaempferol structures showed moderate activities, $197.38 \mu \mathrm{M}$ for 1 and $74.65 \mu \mathrm{M}$ for 2 . It is likely that the xylopyranosyl moiety present in compound 2 is responsible for its greater inhibitory activity compared to compound $\mathbf{1}$, which lacks this sugar. The leishmanicidal activity of $\mathbf{1}$ has already been reported, with $\mathrm{IC}_{50}=70 \mu \mathrm{g} \mathrm{mL} \mathrm{mL}^{-1}(162 \mu \mathrm{M})$ on the amastigote parasite Leishmania amazonensis. ${ }^{34}$ Thus, we can hypothesize that a possible mechanism for the leishmanicidal activity of the flavonoid is $L d \mathrm{NH}$ inhibition. Other mechanisms possibly contribute as well. Other studies report that compound 2 has anti-viral activity with an $\mathrm{EC}_{50}$ of $7.4 \mu \mathrm{g} \mathrm{mL} \mathrm{m}^{-1}$ against HSV1 and $9.0 \mu \mathrm{g} \mathrm{mL}^{-1}$ against HSV-2. ${ }^{30}$ However, tricetin (3) which has only the aglicone showed higher inhibitory activity with an $\mathrm{IC}_{50}$ of $1.06 \mu \mathrm{M}$. The $\mathrm{IC}_{50}$ curves are shown in the ESI (Fig. S4 $\dagger$ ).

To understand the molecular-level interactions of flavonoids 1 and 2 with $L d \mathrm{NH}$, the isolated compounds were analyzed by the NMR Saturation Transfer Difference experiment (NMRSTD). ${ }^{22}$ This pulse sequence allows the identification of the hydrogen atoms of the ligand that participate in interactions with $L d \mathrm{NH}$. The intensities of the STD signals are directly proportional to the distances between the hydrogens of the ligands and the protein. Thus, the more intense STD signals indicate a greater proximity to the protein providing a map of the topology of the interaction.

For flavonoid 1 (Fig. 2A), the STD spectrum shows only weak resonances for the aromatic protons $\mathrm{H}-6$ and $\mathrm{H}-8$ of ring $\mathrm{A}, \mathrm{H}-2^{\prime}$ / $\mathrm{H}-6^{\prime}$ and $\mathrm{H}-3^{\prime} / \mathrm{H}-5^{\prime}$ of ring $\mathrm{B}$, and the methyl protons of rhamnose moiety. For flavonoid 2 (Fig. 2B), the STD signals of the aromatic protons and rhamnose methyl group are much more intense than those observed for flavonoid 1. Furthermore, the signal at $1.00 \mathrm{ppm}$ from the rhamnose methyl group was more intense than the signals of the other sugar protons, confirming the interaction of the rhamnose moiety with $L d \mathrm{NH}$ and suggesting that methyl group is closer to the enzyme. The flavonoid isolated from $U$. rufescens (compound 3) was not analyzed by 
A
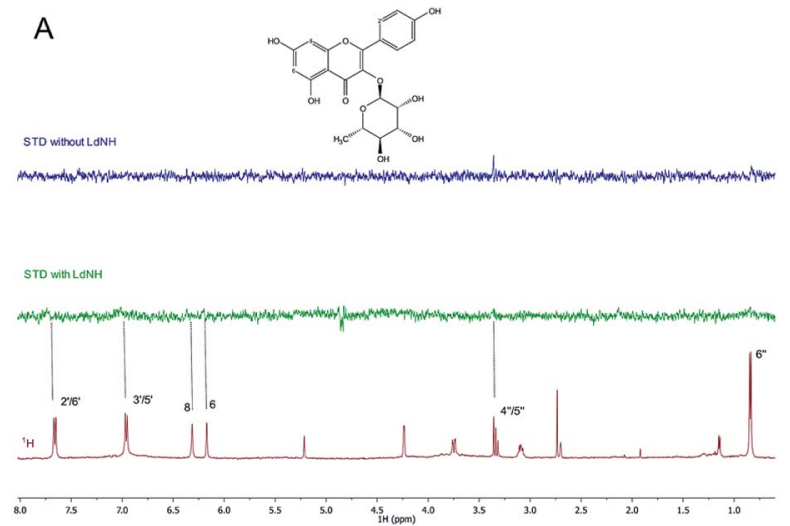

B

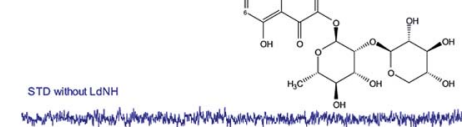

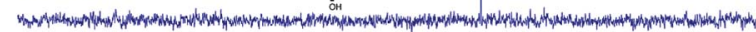

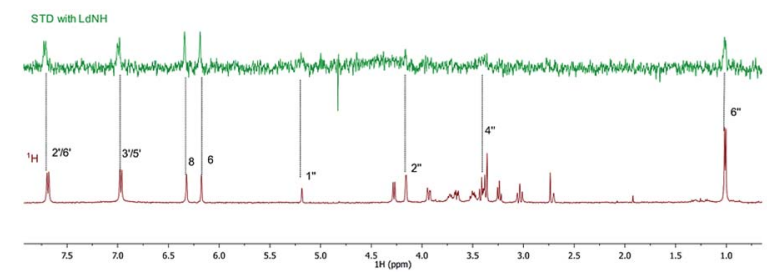

Fig. 2 Representative results of the STD-NMR binding assay. (A) ${ }^{1} \mathrm{H}$ NMR spectra (red) of compound 1 and its STD effects (green). (B) ${ }^{1} \mathrm{H}$ NMR spectra (red) of compound 2 and its STD effects (green). As control, STD experiment was run for each sample in the absence of LdNH (blue).

NMR-STD due to aggregation in aqueous medium at the concentration required for the NMR studies $(>200 \mu \mathrm{M})$. The sugar moiety is an important factor for the bioavailability of the flavonoid derivatives ${ }^{35}$ but is absent in the flavonoid 3 , which makes it less soluble in water than flavonoids 1 and 2 . The NMR-STD data indicates that the sugar could be directly involved in the protein interaction, however, because the nonglycosylated flavonoid 3 has a much higher inhibitory potency than the glycosylated flavonoids, it is clear that the sugar is not essential for $L d \mathrm{NH}$ inhibition.

Considering that the substrates of $L d \mathrm{NH}$ are nucleosides, compounds containing a purine or pyrimidine ring bound to a ribose, suggests that an inhibitor containing a sugar moiety could function as a competitive inhibitor. As the nonglycosylated flavonoid 3 had the highest inhibitory potency, it leads us to believe that flavonoids $\mathbf{1}$ and $\mathbf{2}$ should inhibit $L d \mathrm{NH}$ by a mechanism different than flavonoid 3. In fact, in our previous work with molecular fragments, we identified for the first time a non-glycosylated inhibitor of the $L d \mathrm{NH}^{24}$ This inhibitor was also the first to be described as an noncompetitive inhibitor of this enzyme.

As flavonoid 3 was the most promising $L d \mathrm{NH}$ inhibitor, we carried out kinetics studies to determine the mechanism of inhibition of $L d \mathrm{NH}$. In the first step, we examined the equilibrium enzyme-inhibitor complex (E-I) to evaluate the reversibility of inhibition. In this experiment, after the formation of the complex, a jump dilution was conducted and the rapid recovery of enzymatic activity was observed showing that flavonoid 3 acts as a reversible inhibitor of $L d \mathrm{NH}$.

In the second step, to establish the type of inhibition presented by flavonoid 3 , we investigated which of the classical models of inhibition is most consistent with our results. For this experiment, we analyzed kinetic data for three different concentrations of 3 , with six different concentrations of inosine (Fig. 3). The treatment results were compared with those from control measurements performed in the absence of inhibitor. Non-linear regression was used to consider all data simultaneously and discriminate the inhibition mechanism using different parameters. An uncompetitive (or anti-competitive) model of inhibition statistically best described the results when compared to the competitive, non-competitive and mixed inhibition models. The parameters $V_{\max }\left(\mathrm{mM} \mathrm{min}^{-1}\right)=191(\mathrm{CI} 95 \%=167.8$ to 214.2$)$ and $K_{\mathrm{M}}$ $(\mathrm{mM})=0.37$ (CI 95\% $=0.2428$ to 0.5170$)$ were also determined using global fitting of the data.

Molecular docking was used to explore the interaction mode of flavonoid 3 with $L d \mathrm{NH}$. These data can be used in the later stages for the structural optimization of this inhibitor to aid in the development of a prototype with inhibitory action of $L d \mathrm{NH}$ with greater potency and leishmanicidal action.

The homology model of $L d \mathrm{NH}$ developed and validated was previously published by Alves $e t a .^{24}$ and used in this stage of investigation. Given the uncompetitive inhibition mechanism of flavonoid 3 , the model containing inosine was used to perform the docking assays in an exploratory manner without setting the docking space. For this, the $L d \mathrm{NH}$ model containing the complex with inosine and flavonoid 3, were submitted to the SwissDock server to identify the docking regions.

As observed in Fig. 4A, the three lowest energy docking poses of ligand-protein interaction are located in the same allosteric pocket. This allosteric pocket is located near the catalytic site, which is represented by the presence of inosine

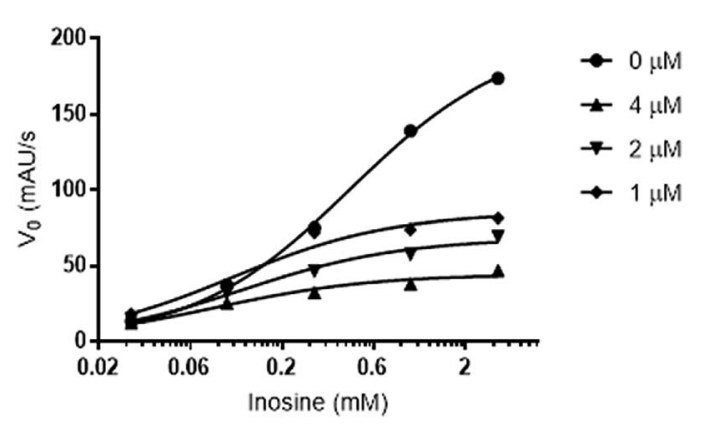

Fig. 3 Concentration-effect curves for the enzymatic activity of $L d N H$ in the presence of compound 3 with different inosine concentrations $(0.03,0.10,0.30,1.00$ and $3.00 \mathrm{mM})$. The experiment was performed in the absence (control ) or presence of increasing concentrations of compound $3(1 \bullet, 2 \boldsymbol{\nabla}$ and $4 \boldsymbol{\Delta} \mu \mathrm{M})$. 

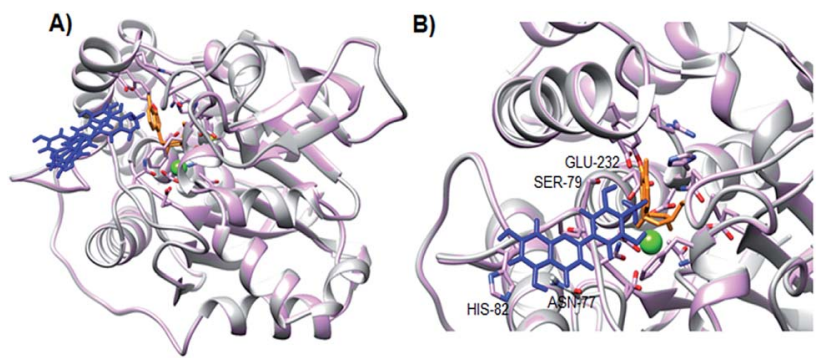

Fig. 4 Docking of flavonoid 3 and $L d N H$-inosine complex. (A) Cartoon representation of $L d N H$ including inosine (orange stick representation), calcium ion (green sphere) and the three lowest energy poses of flavonoid 3 (blue stick representation). (B) The best docking conformation of flavonoid 3 in the complex inosine-bound $L d N H$. Residues of $L d \mathrm{NH}$ within $4 \AA$ of flavonoid 3 are indicated in the figure.

(orange) and the calcium ion (green sphere). The docking pose of the complex with the lowest intermolecular energy $\left(-6.83 \mathrm{kcal} \mathrm{mol}^{-1}\right.$ ) (Fig. 4B) shows that flavonoid 3 interacts with the $L d \mathrm{NH}$ residues of Ser-79, His-82, Glu-232 and Asn-77. Based on these results, our group is now working to optimize the structure of flavonoid 3 aiming to develop a compound with a greater number of interaction points with $L d \mathrm{NH}$ and to evaluate whether the structural changes promote an increase in the potency of the leishmanicidal effect.

\section{Conclusions}

This study demonstrates the great potential of the Brazilian flora in the supply of bioactive compounds, where $10 \%$ of the evaluated extracts presented an inhibitory potential of $L d \mathrm{NH}$ greater than $50 \%$. As phytochemical studies of the selected plants were not found in the literature, we described for the first time the flavonoids kaempferol 3-O- $\alpha$-L-rhamnopyranoside (1) and kaempferol 3-O- $\beta$-D-xylopyranosyl-( $1 \rightarrow 2)-\alpha$-Lrhamnopyranoside (2) for Leandra amplexicaulis DC as well as tricetin-4'-O-methyl flavone (3) for Urvillea rufescens Cambess. Although flavonoids have already been identified as leishmanicidal agents, this is the first time that this class of compounds has been described as inhibitors of $L d \mathrm{NH}$. Flavonoid 3, with an $\mathrm{IC}_{50}$ of $1.06 \mu \mathrm{M}$ and an uncompetitive inhibition mechanism opens a new perspective for the design of new and more potent inhibitors for this enzyme and for the treatment of leishmaniasis.

\section{Conflicts of interest}

There are no conflicts to declare.

\section{Acknowledgements}

This work was supported by the Conselho Nacional de Desenvolvimento Científico e Tecnológico - CNPq (BR) Grant 303647/2015-9, and Fundação Carlos Chagas Filho de Amparo a Pesquisa no Estado do Rio de Janeiro - FAPERJ (BR) Grant E-26/111.483/2013. Authors would like to thank
Coordenação de Aperfeiçoamento de Pessoal de Nível Superior - CAPES for the scholarship to Gregorio Torres and Livia Casanova, and CNPq for the Fellowship 400095/2014-9 to Charlotte Nirma and scholarship to Mayara M. Moreira and Luanna M. Rodrigues. Our sincere thanks to Prof. Cynthia K. Larive (University of California-Riverside) for the careful review of the English language.

\section{References}

$1 \mathrm{WHO}$, Second WHO report on neglected tropical diseases, 2013. 2 J. Alvar, I. D. Vélez, C. Bern, M. Herrero, P. Desjeux, J. Cano, J. Jannin and M. den Boer, PLoS One, 2012, 7, e35671.

3 A. Henderson and D. Jolliffe, Br. J. Clin. Pharmacol., 1985, 19, 73-77.

4 R. Sabra and R. A. Branch, Drug Saf., 1990, 5, 94-108.

5 L. Cui, G. Rajasekariah and S. K. Martin, Gene, 2001, 280, 153-162.

6 M. N. Rennó, T. C. C. França, D. Nico, C. B. Palatnik-DeSousa, L. W. Tinoco and J. D. Figueroa-Villar, Eur. J. Med. Chem., 2012, 56, 301-307.

7 T. C. C. França, M. D. R. M. Rocha, B. M. Reboredo, M. N. Rennó, L. W. Tinoco and J. D. Figueroa-Villar, J. Braz. Chem. Soc., 2008, 19, 64-73.

8 W. Versées, K. Decanniere, E. Van Holsbeke, N. Devroede and J. Steyaert, J. Biol. Chem., 2002, 277, 15938-15946.

9 R. S. Patil, M. S. Patil, S. S. Kshirsagar, P. S. Chaudari, J. P. Bayas and R. J. Oswal, World Journal of Public Health Sciences, 2012, 1, 7-22.

10 T. J. Schmidt, S. A. Khalid, A. J. Romanha, T. M. A. Alves, M. W. Biavatti, R. Brun and F. B. Da Costa, Curr. Med. Chem., 2012, 19, 2176-2228.

11 T. J. Schmidt, S. A. Khalid, A. J. Romanha, M. W. Biavatti, R. Brun, S. L. De Castro, V. F. Ferreira, L. L. Leon, N. P. Lopes, M. Niehues, I. V Ogungbe, A. M. Pohlit, M. T. Scotti, W. N. Setzer, M. Steindel and A. G. Tempone, Curr. Med. Chem., 2012, 19, 2128-2175.

12 P. E. Cockram and T. K. Smith, J. Nat. Prod., 2018, 81, 21382154.

13 A. S. Nagle, S. Khare, A. B. Kumar, F. Supek, A. Buchynskyy, C. J. N. Mathison, N. K. Chennamaneni, N. Pendem, F. S. Buckner, M. H. Gelb and V. Molteni, Chem. Rev., 2014, 114, 11305-11347.

14 Flora do Brasil 2020 Web page. http:// www.floradobrasil.jbrj.gov.br, accessed Feb 27, 2019.

15 E. A. De Camargo and R. Goldenberg, Iheringia, Ser. Bot., 2007, 62, 103-111.

16 A. Frazão, E. Genise and V. Somner, Hoehnea, 2016, 43, 437459.

17 R. Alam, A. T. Barbarovich, W. Caravan, M. Ismail, A. Barskaya, D. W. Parkin and B. J. Stockman, Chem. Biol. Drug Des., 2018, 92, 1736-1742.

18 S. Beck, S. N. Muellers, A. L. Benzie, D. W. Parkin and B. J. Stockman, Bioorg. Med. Chem. Lett., 2015, 25, 50365039.

19 M. Salem and K. Werbovetz, Curr. Med. Chem., 2006, 13, 2571-2598. 
20 D. Tasdemir, M. Kaiser, R. Brun, V. Yardley, T. J. Schmidt, F. Tosun and P. Rüedi, Antimicrob. Agents Chemother, 2006, 50, 1352-1364.

21 T. Polonio and T. Efferth, Int. J. Mol. Med., 2008, 22, 277-286.

22 M. Mayer and B. Meyer, J. Am. Chem. Soc., 2001, 123, 61086117.

23 O. H. Lowry, N. J. Rosebrough, A. L. Farr and R. J. Randall, J. Biol. Chem., 1951, 193, 265-275.

24 M. A. Alves, C. Nirma, M. M. Moreira, R. O. Soares, P. G. Pascutti, F. Noël, P. R. R. Costa, C. M. R. Sant'Anna, E. J. Barreiro, L. M. Lima and L. W. Tinoco, RSC Adv., 2016, 6, 87738-87744.

25 R. A. Copeland, Evaluation of Enzyme Inhibitors in Drug Discovery: A Guide for Medicinal Chemists and Pharmacologists, John Wiley \& Sons, Inc., New Jersey, 1st edn, 2005.

26 C. Dalvit, J. Biomol. NMR, 1998, 11, 437-444.

27 A. Grosdidier, V. Zoete and O. Michielin, Nucleic Acids Res., 2011, 39, W270-W277.
28 L. Kerhoas, D. Aouak, A. Cingöz, J.-M. Routaboul, L. Lepiniec, J. Einhorn and N. Birlirakis, J. Agric. Food Chem., 2006, 54, 6603-6612.

29 H. Soicke, K. Görler and H. Waring, Planta Med., 1990, 56, 410-412.

30 F. G. G. Ürményi, G. do N. Saraiva, L. M. Casanova, A. dos S. Matos, L. M. de Magalhães Camargo, M. T. V. Romanos and S. S. Costa, Chem. Biodiversity, 2016, 13, 1707-1714.

31 H. J. Lee, D. Ahn, E. B. Lee, T. G. Lee and D. K. Kim, Saengyak Hakhoechi, 2013, 44, 16-17.

32 A. Ulubelen, T. J. Mabry, G. Dellamonica and J. Chopin, J. Nat. Prod., 1984, 47, 384-385.

33 E. Wollenweber, R. Wehde, M. Dörr and J. F. Stevens, $Z$. Naturforsch., C: J. Biosci., 2002, 57, 445-448.

34 M. F. Muzitano, L. W. Tinoco, C. Guette, C. R. Kaiser, B. Rossi-Bergmann and S. S. Costa, Phytochemistry, 2006, 67, 2071-2077.

35 P. C. H. Hollman and I. C. W. Arts, J. Sci. Food Agric., 2000, 80, 1081-1093. 